\title{
ATUAÇÃO DA ENFERMEIRA OBSTETRA NO DESENROLAR DO TRABALHO DE PARTO E PARTO
}

\section{ROLE OF THE OBSTETRIC NURSE IN THE DEVELOPMENT OF LABOR AND DELIVERY}

\section{PAPEL DE LA COMADRONA EN EL CURSO DEL PARTO Y EL ALUMBRAMIENTO}

Tâmara Taiane Mangueira Alves ${ }^{1}$, Gilvânia Patrícia do Nascimento Paixão ${ }^{2}$, Chalana Duarte de Sena Fraga ${ }^{3}$, Josinete Gonçalves dos Santos Lírio ${ }^{4}$, Francieli Aparecida de Oliveira ${ }^{5}$

\begin{abstract}
RESUMO
Objetivo: analisar a atuação das enfermeiras obstetras, no desenrolar do trabalho de parto e parto, a partir dos seus relatos. Métodos: trata-se de uma pesquisa descritiva, exploratório de abordagem qualitativa. A coleta de dados foi através da entrevista semiestruturada. As participantes foram quatro enfermeiras obstetras do município de Senhor do Bonfim/BA. Para melhor organizar os dados, foi utilizada a análise de conteúdo proposta por Bardin, sendo o material separado em categorias temáticas. Resultados: os achados revelam que o trabalho da enfermeira obstetra vai para além de prestar assistência de qualidade à puérpera e ao bebê. Sua atuação também se relaciona à boa comunicação com pacientes e familiares, bem como o atendimento humanizado e integral, sendo considerado de fundamental importância. Conclusão: a importância da atuação da enfermeira obstetra nos ambientes parturitivos foi evidenciada, visto ser esta uma profissional habilitada e essencial para a prática do parto humanizado e fisiológico.
\end{abstract}

Descritores: Enfermeira obstetra; Trabalho de parto; Humanização da Assistência.

\section{ABSTRACT}

Objective: to analyze the performance of obstetrical nurses in the course of labor and delivery, based on their reports. Methods: This is a descriptive, exploratory research with a qualitative approach. The data collection was through the semistructured interview. The participants were four obstetrician nurses from Senhor do Bonfim/Bahia/Brazil. To organize better the data, we used the content analysis proposed by Bardin, the material being organized into thematic categories. Results: the findings reveal that the work of the obstetrician nurse goes beyond providing good care to the puerperal and the baby. His work is also related to good communication with patients and family, as well as the humanized and integral care, being considered of fundamental importance. Conclusion: the importance of obstetrical nurse performance in parturient environments was evidenced, since this is a qualified professional and essential for the practice of humanized and physiological delivery.

Keywords: Nurse-midwives; Labor obstetric; Humanization of assistance.

\footnotetext{
${ }^{1}$ Enfermeira. Graduada pela Universidade do Estado da Bahia/UNEB, Campus VII, Senhor do Bonfim-BA.

${ }^{2}$ Doutora em Enfermagem. Enfermeira Obstetra e consultora em Aleitamento Materno.

${ }^{3}$ Professora auxiliar da Universidade Estadual da Bahia /UNEB, Campus VII, Senhor do Bonfim-BA. Enfermeira Obstetra. Mestra em Enfermagem.

${ }^{4}$ Enfermeira. Mestranda em Enfermagem pela Escola de Enfermagem da Universidade Federal da Bahia.

${ }^{5}$ Graduanda em Enfermagem pela Universidade do Estado da Bahia/UNEB, Campus VII, Senhor do Bonfim-BA.
} 


\section{RESUMEN}

Objetivo: analizar la actuación de las enfermeras obstetras, en el desarrollo del trabajo de parto y parto, a partir de sus relatos. Métodos: se trata de una investigación descriptiva, exploratoria de abordaje cualitativo. La recolección de datos fue a través de la entrevista semiestructurada. Las participantes fueron cuatro enfermeras obstetras del municipio de Senhor do Bonfim / BA. Para mejor organizar los datos, se utilizó el análisis de contenido propuesto por Bardin, siendo el material organizado en categorías temáticas. Resultados: los hallazgos revelan que el trabajo de la enfermera obstetra va más allá de prestar asistencia a la puérpera y al bebé. Su actuación también se relaciona con la buena comunicación con pacientes y familiares, así como la atención humanizada e integral, siendo considerado de fundamental importancia. Conclusión: la importancia de la actuación de la enfermera obstetra en los ambientes parturitivos fue evidenciada, ya que ésta es una profesional habilitada y esencial para la práctica del parto humanizado y fisiológico.

Palabras clave: Enfermeras obstetrices; Trabajo de parto; Humanización de la atención.

\section{INTRODUÇÃO}

O parto é um evento único, onde o respeito e a valorização das experiências de cada mulher são fundamentais ao período que envolve o início do trabalho de parto (TP), parto e nascimento, com necessidade de conscientização do profissional que parteja, para a maneira como a qual as parturientes preferem viver esse momento. Neste contexto, a participação da enfermeira obstetra é fundamental, uma vez que a prática de seus cuidados é de suma importância para humanizar a assistência. ${ }^{1}$

A enfermeira obstetra deve seguir um modelo de assistência que busque resgatar valores como o protagonismo, a individualidade, a privacidade e a autonomia da mulher, objetivando a promoção de partos saudáveis, eliminando intervenções desnecessárias e oferecendo outras comprovadamente benéficas. ${ }^{2}$ Dentre os cuidados, essa profissional deve estar alerta às queixas e outras manifestações que possam indicar algum tipo de intercorrência, informando a gestante sobre sua evolução no TP e sugerindo-lhe condutas a serem tomadas para tornar o momento mais agradável. ${ }^{3}$ Para assumir esse trabalho, a enfermeira deve ser especialista em obstetrícia, formação que lhe dará suporte para assumir condutas indicadas para a execução do parto sem distorcias, ${ }^{3}$ conforme resolução que regulamenta o exercício profissional. ${ }^{4}$

Diante esta perspectiva, o este estudo teve como questão norteadora: qual a atuação da enfermeira obstetra no desenrolar do trabalho de parto e parto? Para responder à tal questionamento, delineou-se o objetivo de analisar a atuação da enfermeira obstetra no desenrolar do trabalho de parto e parto.

\section{METODOLOGIA}

Estudo exploratório, de abordagem qualitativa. $^{5}$ As pesquisas qualitativas se caracterizam pelo tratamento dado às 
informações coletadas e a sua organização e análise, que, ao invés de ter os métodos estatísticos como principal finalidade, tem como meta final aspectos acerca da complexidade do objeto de estudo, como foi o caso deste trabalho. Através desta abordagem foi possível analisar a complexidade da atuação da enfermeira no trabalho de parto e parto.

$\mathrm{O}$ estudo foi realizado no município Senhor do Bonfim, localizado ao norte do Estado da Bahia, com 376 km de distância da capital do estado. Possui uma população com mais de 80 mil habitantes, considerado como centro de confluência de uma região chamada Piemonte Norte do Itapicuru. Esta, abrange municípios como: Campo Formoso, Jaguarari, Andorinha, Ponto Novo, Caldeirão Grande, Pindobaçu, Filadélfia e Antônio Gonçalves.

As colaboradoras deste estudo foram quatro enfermeiras obstetras, que atuam tanto na atenção básica como na área hospitalar. Para captação dos sujeitos do estudo foi usada a técnica de "Bola de neve", que é uma forma de amostra não probabilística utilizada em pesquisas sociais. Seu ponto de partida consiste em estabelecer o perfil dos informantes-chave, que são nomeados de sementes, a fim de localizar algumas pessoas com o perfil correspondente necessário para a pesquisa. Identifica-se as participantes da pesquisa a partir da rede de contato das sementes. $\mathrm{Na}$ sequência, solicita-se que as pessoas indicadas pelas sementes indiquem novas pessoas dentro do perfil estabelecido, e assim sucessivamente até a saturação. É entendido como "ponto de saturação" da amostragem quando os sujeitos não apresentam novas informações ou dados relevantes para a análise, ou quando a rede de contatos chega ao fim. ${ }^{6}$

Salienta-se que apesar de considerar a saturação já atingida, ainda tentamos o contato com outras duas enfermeiras profissionais indicadas, porém estas recusaram-se a participar da pesquisa. Acrescenta-se ainda que os critérios de inclusão foram: ser enfermeiras especialistas em obstetrícia e atuarem no município lócus da pesquisa.

A coleta de dados ocorreu entre os meses de fevereiro e maio de 2017, por meio de entrevista com formulário semiestruturado, que permitiu às entrevistadas ponderar sobre o tema, sem se prender à investigação formulada. A entrevista é a estratégia mais usada no método de trabalho de campo, e acima de tudo uma conversa entre duas ou mais pessoas, a fim de construir informações relacionadas para um objeto de pesquisa. ${ }^{5}$

Para organizar os achados, foi empregada a técnica de análise de conteúdo de Bardin. ${ }^{7}$ Esta metodologia é feita através das três etapas básicas: préanálise, exploração do 
material/categorização e interpretação dos resultados. A pré-análise é a fase em que se organiza o material a ser analisado com o objetivo de torná-lo operacional, sistematizando as ideias iniciais. A exploração do material, segunda fase, é o momento onde se explora o material e se definem as categorias e unidades de registro e contexto. A última etapa, interpretação dos resultados, é a fase da descrição analítica, onde o material é submetido a um estudo aprofundado, orientado pelas hipóteses e referenciais teóricos. ${ }^{8} \mathrm{~A}$ discussão dos resultados foi feita a partir da literatura científica sobre o tema.

Para realização deste estudo foram atendidas as exigências dispostas na Resolução 466/12 do Ministério da Saúde (Conselho Nacional de Saúde/Comissão Nacional de Ética em Pesquisa), que dispõe sobre pesquisas que envolvem seres humanos, com base nos referenciais básicos da bioética autonomia, justiça, beneficência e não maleficência. ${ }^{9} \mathrm{O}$ estudo foi aprovado pelo Comitê de Ética em Pesquisa da Universidade do Estado da Bahia, sob o parecer de número: 1.562 .054 .

Inicialmente, às candidatas a participante do estudo, foram apresentados os objetivos da pesquisa, e abordados os benefícios do estudo, confidencialidade dos dados gerados, de modo a esclarecer que as publicações não permitirão identificação das participantes. Aceitando participar do estudo, foi solicitada a leitura do Formulário de Informação às Participantes e assinatura do Termo de Consentimento Livre e Esclarecido (TCLE), ficando as colaboradoras com a via original do TCLE.

\section{RESULTADOS}

A partir da análise temática de Bardin sob o material empírico coletado, foi possível apreender seis categorias que permitiram analisar o trabalho da enfermeira obstetra.

\section{Categoria 1 - Assistência prestada pela Enfermeira Obstetra}

Nesta categoria, as entrevistadas desvelam a assistência prestada pela enfermeira obstetra, sendo que dois subnúcleos do sentido se destacaram: a atuação global à gestante e a atuação específica no trabalho de parto e parto.

\section{Atuação global à gestante}

As participantes do estudo referem que a atuação global da enfermeira obstetra se dá tanto na atenção primária como em setores múltiplos do hospital, como: triagem, sala de parto e alojamento conjunto. A assistência prestada mesmo antes do trabalho de parto é reconhecida como de grande relevância para o 
desenrolar do período parturitivo. Dispõem ainda sobre a importância da humanização e do trabalho em equipe, conforme relatos à seguir:

Atua desde o acolhimento da gestante antes ou em trabalho de parto até o puerpério no alojamento, de uma forma humanizada, procurando ver todos os sintomas para resolver da melhor forma possível, junto com a toda a equipe. (Enfa 01)

Enfermeiro obstetra ele atua desde a atenção primária, que é muito importante no caso, para receber a gestante e preparar para o parto. (Enfa 02)

Tem muita autonomia dentro do ambiente hospitalar, atua desde a chegada da paciente ao hospital, recebendo, examinando, avaliando, $e$ conduzindo. (Enfa 03)

\section{Atuação específica no trabalho de parto e parto.}

A atuação no trabalho de parto e parto foi caracterizada pelo acolhimento e pelos cuidados que envolvem observar a dinâmica do trabalho de parto, dilatações, distorcias, e diminuam o desconforto físico e emocional.

O papel da enfermeira é acompanhar a evolução do trabalho de parto, observar as dilatações, a dinâmica do trabalho de parto, logo após o parto e também observar a gestante e o RN na tentativa de minimizar os agravos. (Enfa 01)

Acompanhar de forma ativa a parturiente no trabalho de parto, estimulando pra o parto natural, identificando também as distorcias ou desproporções, preenchendo o partograma, realizando também a monitorização fetal. (Enfa 03)
Acolher a parturiente, prestar cuidados no sentindo de diminuir o desconforto físico $e$ emocional, tornar o parto o mais natural possível. (Enfa 04)

\section{Categoria 2 - Importância da presença} da enfermeira obstetra nos serviços de atenção ao parto.

As entrevistadas expõem que a importância da enfermeira obstetra nos serviços de atenção ao parto, se dá pelo vínculo que é estabelecido entre parturiente e profissional. Para além da assistência, a enfermeira consegue promover um parto tranquilo e seguro, o que é essencial para um serviço humanizado.

A equipe de enfermagem está mais vinculada ao paciente, acompanha a gestante desde o início até o final. Presta a sistematização da assistência de forma integral. (Enfa 01)

Papel mais importante nesse momento da enfermeira é justamente em relação ao parto humanizado. É importante ter a enfermeira nesse momento do parto por passar segurança até pra gestante, pelo fato da enfermeira acolher a parturiente antes, durante e pós parto.(Enfa 02)

A enfermeira obstetra é quem faz escuta qualificada, oferece uma assistência livre de danos e com isso as parturientes se sentem mais seguras durante o trabalho de parto. (Enfa 04)

\section{Categoria 3 - Comunicação aberta com a parturiente}

As participantes expuseram que a comunicação entre a parturiente e a enfermeira/equipe obstétrica deve ocorrer da melhor maneira possível, ouvindo 
queixas, prestando orientações, a fim de transmitir segurança para a mulher.

Da melhor forma possível, ouvir a paciente, dar abertura para criar um vínculo. (Enfa 01)

Deve ocorrer uma comunicação direta entre a equipe e a mulher, para transmitir segurança para a parturiente. (Enfa 02)

De forma clara, acolhedora, retirando todas as suas dúvidas, respondendo todas as suas queixas, mantendo informada sempre em tudo que pode estar acontecendo né, ser apoio também através dessa comunicação. (Enfa 03)

A enfermeira deve realizar uma escuta de qualidade, tirar dúvidas da parturiente, apoiar $e$ transmitir tranquilidade. (Enfa 04)

\section{Categoria 4 - Humanização da assistência ao parto}

Para as entrevistadas, a melhor palavra que define a humanização é o acolhimento, e este ocorre antes mesmo do início do trabalho de parto. Como resultado disso, tem-se uma gestante informada e segura.

O termo humanização vem da palavra acolher, acolher da melhor forma possivel, desde o simples cadastro de uma ficha, com o nome, o que ela está sentindo, explicar o que vai acontecer com ela por que muitas são marinheiras de primeira viagem ou até o terceiro filho, e nenhuma gestação, nenhum parto é igual ao outro, a gente tem que explicar. A gente tem que orientar como minimizar essa dor, as técnicas de agachamento, de massagem na região lombar e tentar minimizar a ansiedade. (Enfa 01)

Saber ouvir, acolher e prestar uma boa assistência de enfermagem. (Enfa 02)
Enfermeira obstetra caminha muito mais na linha de humanização, com o trabalho de parto $e$ parto sem intervenções. Isso para mulher é muito importante porque ela se torna mais autônoma no processo. (Enfa 03)

É colocar-se no lugar daquela parturiente e só sabermos a real necessidade que ela tem. (Enfa 04)

\section{Categoria 5 - Experiências vivenciadas}

As experiências vivenciadas perpassaram por momentos bons e ruins, quando puderam contar com a participação de outros profissionais, mas também períodos em que precisaram agir sozinhas.

Ela (preceptora) falou bem assim: "leva ela (mulher) pra sala de parto e vai fazendo o parto". Quando eu estou fazendo o parto, como ela (preceptora) havia orientado, a técnica falou: está demorando demais. Fez a manobra de Kristeller, a criança saiu rasgando tudo, e eu fiquei sem reação. (Enfa 01)

A mulher começou a parir e eu comecei a ficar desesperada sem saber o que fazer, me vi naquele momento sozinha e era só eu e eu mesma e foi o primeiro parto que eu fiz. No momento que eu vi a criança coroando eu só disse assim é, "se eu estou aqui, eu estou por algum motivo”. (Enfa 02)

Adolescente 13 anos e já estava vindo a bolsa das águas na frente, ela saiu da sala de exames e já foi direto pra sala de parto, chegou lá a paciente já pariu assim. Mas a única vez que aconteceu comigo por isso marcou, o bebê vinha com uma circular e o cordão rompeu praticamente só, e imediatamente a placenta saiu. (Enfa 03)

Me marcou um parto de gêmeos que eu realizei, a médica estava comigo na sala, mas quem prestou toda assistência fui eu. Me marcou pois foi o primeiro parto de gêmeos que presenciei $e$ 
participei realizando o mesmo, foi marcante. (Enfa 04)

\section{Categoria 6 - Desafios da enfermeira obstétrica durante o trabalho de parto e parto}

Nesta categoria as enfermeiras evidenciaram os desafios enfrentados durante o trabalho de parto e parto. Ressaltaram a importância do acolhimento para que o parto possa fluir bem, esperando-se que assim ocorra a redução de intercorrências. Citaram também sobre a problemática do trabalho em equipe e do amparo para com a família, que muitas vezes se torna uma tarefa difícil, principalmente quando as notícias não ocorrem como se espera.

Os desafios são [muitos] porque se estuda de uma forma dentro da instituição hospitalar da especialização, e quando vai pra instituição hospitalar é outra forma. (Enfa 01)

O maior desafio é a família absorver ou aceitar o trabalho parto demorado, porque tem trabalho de parto que são bem mais demorados e muitas vezes a família fica num estado de tensão de querer uma resolução rápida. (Enfa 03)

\section{DISCUSSÃO}

O estudo evidenciou que o trabalho da enfermeira obstetra perpassa por diferentes nuances, sendo que a assistência prestada ocorre antes, durante e após o trabalho de parto e parto. Corroborando, autoras expõem que a enfermeira atua frente à gestante em diversos momentos, incluindo a consulta de pré-natal, parto e puerpério. Ressaltam ainda que estes são momentos de grande importância para a mulher, visto que ocorre troca de experiências, conhecimento e a compressão do processo gestar. $^{10}$

Nesse contexto, as participantes do estudo percebem que a enfermeira é essencial para empoderar a gestante, através da maior adesão ao pré-natal, garantindo a qualidade na assistência e melhores resultados obstétricos e perinatais. Acreditam ainda, que a Enfermeira é uma profissional capaz de prestar um acompanhamento completo para a mulher, desde os momentos que antecedem a sua gestação, até o momento do parto e pós-parto. Também é uma profissional considerada apta a fazer o acompanhamento fidedigno, escuta qualificada e atendimento humanizado. Uma pesquisa realizada em Belo Horizonte, Minas Gerais, Brasil, revelou que a participação da enfermeira obstetra nos serviços de atenção pode favorecer o equilíbrio entre as intervenções necessárias e o processo fisiológico da parturição ${ }^{11}$, o que irá proporcionar menos intervenções desnecessárias, centrando sua atenção nas reais necessidades.

Para que a assistência contemple todas as demandas das clientes, as entrevistadas enfatizam que a comunicação 
entre a equipe e a parturiente deve ocorrer da forma mais satisfatória possível, tendo em vista a sua fundamental importância nos momentos que antecedem o trabalho de parto e parto. Isso porque, se a comunicação é eficiente, todas as demandas serão apontadas e mais facilmente supridas, o que faz com que as parturientes se sintam seguras nesse momento. Tal achado também foi referido por estudiosos da área ${ }^{12}$, demonstrando que o suporte dos profissionais de saúde durante o processo do parto às mulheres, permite a criação de laços de confiança e afeição, o que facilita o cuidado e conforto.

Baseado nessa compreensão, destaca-se durante todo o estudo a humanização da assistência, visto que as enfermeiras obstetras entrevistadas entendem a importância, compreendem seu significado e ainda o fato de que deve ser um elemento presente muito antes do momento do parto. Salienta-se que o principal entendimento sobre o termo 'humanizar' é o de 'acolher' a mulher, dando-lhe toda autonomia que precisa.

Corroborando com esta ideação, autores definem que "Humanizar o parto é dar às mulheres o direito a um atendimento focado em suas necessidades, respeitando a sua individualidade e seus desejos". ${ }^{13}$ Outros autores ainda incluem fatores diversos no termo humanização, que são: "respeitar e criar condições para que todos os aspectos do ser humano sejam atendidos: espirituais, psicológicas e biológicas". ${ }^{14}$

Nesse sentido, quando a enfermeira compreende a importância de humanizar e qualificar a atenção à gestante, está garantindo a qualidade na assistência, o que repercute em melhores resultados obstétricos, com uma postura acolhedora, respeitosa, os profissionais atendem às expectativas e necessidades da mulher. ${ }^{10} \mathrm{~A}$ partir dessas questões, as participantes relataram diversas experiências, positivas e negativas, que vivenciaram enquanto enfermeiras obstetras. As experiências negativas foram visualizações de técnicas inapropriadas realizadas por outros membros da equipe, como no exemplo da manobra de Kristeller. Esta técnica obstétrica propõe aplicação de pressão na parte superior do útero durante o trabalho de parto, com objetivo de facilitar a saída do bebê. No entanto, estudos mostram que esta manobra consiste numa prática arriscada, desnecessária e danosa a mulher, que causa desconforto e dor durante sua realização, podendo ser considerada uma violência ao direito da mulher e ao seu corpo. $^{15}$

Salienta-se também que os maiores desafios relatados pelas participantes foram: a estrutura disponível nos hospitais maternidades, que divergem muitas vezes do que é preconizado; e a comunicação 
com as famílias, que nem sempre compreendem que o trabalho de parto pode ser algo demorado.

\section{CONSIDERAÇÕES FINAIS}

Ao final do estudo foi possível considerar que o trabalho da enfermeira obstetra é de fundamental importância, tanto nos momentos que antecedem o parto, como no parto e puerpério. Compreende-se que o cuidado, o acolhimento, o tratamento humanizado prestado pela enfermeira obstetra durante essas etapas, são fatores imprescindíveis e que reforçam a importância da presença da enfermeira obstetra numa equipe multiprofissional e durante todo o ciclo gravídico-puerperal.

Também foram revelados desafios a serem enfrentados pelas profissionais, que justificam o fato de que mesmo a enfermeira estando presente nesses momentos, nem sempre é possível garantir um cuidado ideal, nem um acolhimento fidedigno, e que uma família que não entende e nem respeita o tempo que a mãe e o bebê precisam, são problemas comuns e que prejudicam o bom andamento desse momento.

Por fim, embora o estudo limite-se pelo pequeno número de participantes, as informações apresentadas foram suficientes para evidenciar a importância da atuação da enfermeira obstetra nos ambientes parturitivos, por ser esta uma profissional habilitada e essencial para a prática do parto humanizado e fisiológico.

\section{REFERÊNCIAS}

1. Velasque EAG, Pradebon VA, Cabral FB. O enfermeiro no processo parir/nascer: estratégia de cuidado e humanização do parto. Rev Enferm UFSM.[Internet]. 2011 [citado em 01 ago 2017]; 1(1):80-87. Disponível em: https://periodicos.ufsm.br/reufsm/article /view/1991

2. Silva MG, Marcelino CM, Rodrigues LSP, Toro CR, Shimo AKK. Violência obstétrica na visão de enfermeiras obstetras. Rev Rene [Internet]. 2014 [citado em 01 ago 2017]; 15(4):720-8. Disponível em: http://www.repositorio.ufc.br/bitstream/ riufc/11479/1/2014_art_mgsilva.pdf

3. Santos GS, Souza JLO, Almeida LS, Gusmão LH. A importância do enfermeiro no atendimento humanizado no pré-parto. Diálogos Ciênc. [Internet]. 2012 [citado em 01 ago 2017]; 10(31):224-228. Disponível em: http://dialogos.ftc.br

4. Presidência da República (Brasil). Lei $n^{\circ} 7.498$, de 25 de junho de 1986.

Dispõe sobre a regulamentação do exercício da Enfermagem e dá outras providências. D.O.U., Brasília, DF, 26 jun 1989. Disponível em: https://presrepublica.jusbrasil.com.br/le gislacao/128195/lei-7498-86

5. Minayo MCS. Pesquisa social: teoria, método e criatividade. 29ed. Petrópolis, RJ: Vozes; 2010. 108p.

6. Vinuto J. A Amostragem bola de neve na pesquisa qualitativa: um debate em aberto. Temáticas [Internet]. 2014 [citado em 01 ago 2017]; 22(44):203220. Disponível em: https://www.ifch.unicamp.br/ojs/index.p hp/tematicas/article/view/2144/1637

7. Urquiza MA, Marques DB. Análise de conteúdo em termos de Bardin aplicada 
à comunicação corporativa sob o signo de uma abordagem teórico-empírica. Entretextos [Internet]. 2016 [citado em 27 jul 2017]; 16(1):115-144. Disponível em:

http://www.uel.br/revistas/uel/index.php /entretextos/article/view/20988/20014

8. Santos FM. Análise de conteúdo: a visão de Laurence Bardin. Rev Eletrônica Educ. [Internet]. 2012; 6(1)383-387. Disponível em http: http://www.reveduc.ufscar.br/index.php /reveduc/article/view/291/156

9. Conselho Nacional de Saúde (Brasil). Resolução $n^{\circ}$ 466, de 12 de dezembro de 2012. Brasília, DF: CONEP; 2012. Disponível em: http://www.conselho.saude.gov.br/resol ucoes/2012/Reso466.pdf

10. Spindola T, Progianti JM, Penna LHG. Opinião das gestantes sobre acompanhamento da enfermeira obstetra no pré-natal de um hospital universitário. Ciênc Enferm. [Internet]. 2012 [citado em 27 jul 2017]; 2(8):6573. Disponível em: http://www.scielo.cl/scielo.php?script=s ci_arttext\&pid=S071795532012000200007

11. Lima MJ, Leite AR, Duarte VF, Borges ES, Fernandes NT. A utilização do partograma pela enfermagem no trabalho de parto sem distocia. Rev Univ Vale Rio Verde. [Internet]. 2017 [citado em 27 jul 2017]; 15(1)537-546. Disponível em: http://periodicos.unincor.br/index.php/r evistaunincor/article/viewFile/2813/pdf _651

12. Oliveira JDG, Campo TNC, Souza FMLC, Davim RMB, Dantas JC. Percepção de enfermeiros obstetras na assistência à parturiente. Rev Enferm UFPE on line. [Internet]. 2016 [citado em 27 jul 2017]; 10(10):3868-75.

Disponível em: http://pesquisa.bvsalud.org/bvsecuador/r esource/pt/bde-30118

13. Pereira SS, Oliveira ICMS, Santos JBS, Pessanha MC, Carvalho, MCMP. Parto natural: a atuação do enfermeiro diante da assistência humanizada. Tempus (Brasília). [Internet]. 2016 [citado em 27 jul 2017]; 10(3):199-213. Disponível em:

http://www.tempusactas.unb.br/index.p hp/tempus/article/view/1727

14. Porto AAS, Costa LP, Velloso NA. Humanização da assistência ao parto natural: uma revisão integrativa. Ciênc Tecnol. [Internet]. 2015 [citado em 27 jul 2017]; 1(1):12-19. Disponível em: http://revistaeletronica.unicruz.edu.br/in dex.php/CIENCIAETECNOLOGIA/arti cle/view/284/528

15. Sousa AMM, Souza KV, Rezende EM, Martins EF, Campos D, Lansky S. Práticas na assistência ao parto em maternidades com inserção de enfermeiras obstétricas, em Belo Horizonte, Minas Gerais. Esc Anna Nery Ver Enferm. [Internet]. 2016 [citado em 27 jul 2017]; 20(2):324-331. Disponível em:

http://www.scielo.br/scielo.php?script=s ci_arttext\&pid=S1414$81452016000200324 \& \operatorname{lng}=\mathrm{en}$. http://dx.doi.org/10.5935/14148145.201

RECEBIDO: $16 / 08 / 2017$

APROVADO: $21 / 02 / 2018$ PUBLICADO: 07/2018 